\title{
Reseña de Lozano Renieblas, Isabel y Fernando Romo Feito, Sales cervantinas. Cervantes y lo jocoserio, México, Ficticia, 2018, 253 pp. ISBN: 978-60-752-1090-2
}

\section{Guillermo Molina Morales}

Instituto Caro y Cuervo

COLOMBIA

Guillermo.Molina.Morales198@gmail.com

[Hipogrifo, (issn: 2328-1308), 7.1, 2019, pp. 731-734]

Recibido: 31-01-2019/ Aceptado: 15-02-2019

DOI: http://dx.doi.org/10.13035/H.2019.07.01.54

¿Queda algo por decir de Cervantes? Lozano y Romo, autores del ensayo Sales cervantinas, son conscientes de la dificultad de proponer lecturas novedosas tras cientos y miles de estudios anteriores. Sin embargo, justifican la oportunidad de este libro de dos maneras: primera, porque aquí se ofrece una visión del conjunto de la obra cervantina, no solo de Don Quijote; segunda, porque la risa ha sido un fenómeno estético menos atendido por la crítica que la seriedad. El primer argumento se vuelve relevante cuando advertimos que existe en Cervantes una clara evolución entre dos maneras muy diferenciadas de entender la risa. El segundo, cuando apreciamos la diversidad de las manifestaciones de la risa en las obras, así como la unidad esencial del fenómeno, que va mucho más allá de la simple carcajada.

En consonancia con las dos grandes facetas de la risa en Cervantes, el ensayo se puede dividir en dos trayectos. El primero, «La risa como turpitudo», abarca La Galatea, la poesía, el teatro y el Quijote de 1605. El segundo, que se sustenta en la idea de lo jocoserio, correspondería a los capítulos segundo («Risa y seriedad en las Novelas ejemplares, El Quijote de 1615 y el Persiles»), tercero («Géneros cómicos y oralidad») y cuarto («La recuperación de lo mágico-maravilloso»). Según se dice en la introducción, los dos autores se responsabilizan de la totalidad del libro. Sin embargo, las diferencias de estilo son notorias: la primera mitad del libro prefiere un recorrido analítico, obra por obra y rasgo por rasgo, mientras que la segunda se inclina hacia la síntesis y se organiza en torno a categorías estéticas. 
Quizás por este motivo en la primera parte destaca la atención a la multiplicidad de manifestaciones de la risa. Por ejemplo, en el Quijote de 1615 se distingue entre la sátira literaria (presente sobre todo en el prólogo), la parodia de personajes, la parodia de formas compositivas, la risa ligada a los sucesos, al diálogo entre los protagonistas y al discurso (en especial, a la mezcla de registros lingüísticos). Es posible que la categorización pudiera haber sido más rigurosa (por ejemplo, en «El diálogo y la risa» se distingue entre burla, risa festiva, risa simpática y la corporalidad, subcategorías que no se limitan a los diálogos), pero este hecho se compensa por la atención al detalle y el acierto de las observaciones críticas.

Si bien la risa siempre ha formado parte esencial de las lecturas de Don Quijote (a pesar de algunos intentos de interpretación seria, sobre todo de raíz romántica) y de las obras teatrales cómicas (las comedias y los entremeses), puede resultar más novedosa esta perspectiva para estudiar La Galatea. La obra ha sido habitualmente considerada como novela pastoril, pero los autores la conciben como égloga, género que supera las diferencias entre poesía y prosa. Con todo, lo principal en el estudio es la vinculación de la obra al cronotopo idílico (es aquí evidente la influencia de Bajtín), lo que explica la importancia de la alegría colectiva, de la utopía, de la conexión entre amor y risa, y de la poesía como manifestación de lo alegre.

En cuanto al género poético, los autores hacen un notable esfuerzo para estudiarlo de manera conjunta, lo que incluye la poesía exenta, la incluida en obras mayores y el Viaje del Parnaso. La risa se manifiesta de manera diferente en cada uno de los casos. Poemas exentos como el dedicado al túmulo de Felipe II en 1598 apuestan por la ironía como forma de mostrar una voz desengañada. Los incluidos en el Quijote de 1605, en cambio, se caracterizan por lo burlesco en su variedad paródica, además de por un complejo juego de máscaras. Distinta función tienen los versos en las Novelas ejemplares, donde se ligan a la alegría y a la picaresca popular. En cuanto al Viaje del Parnaso, el poema se articula como un elogio a la poesía y una sátira (con rasgos de menipea) contra los poetas.

En conjunto, las formas de la risa en la primera etapa de la escritura cervantina se agrupan bajo el término turpitudo, que usaban los tratadistas latinos para referirse a la risa más atenta a la ridiculización de los defectos y, por lo tanto, a la sensación de superioridad de la persona que ríe. Esto acercaría al primer Cervantes a la pura farsa, lo que devaluaría su valoración crítica. A fin de cuentas, este tipo de risa se vincula a la grosería popular, más que a la elegancia cortesana. Ante esto, los autores sostienen que el autor del Quijote no se reduce a lo bufonesco, sino que incorpora también otras formas de risa, como pueden ser la ironía y la complejidad de los protagonistas. Con esos rasgos, nos aproximamos a la segunda etapa de la escritura cervantina, marcada por lo jocoserio.

Según los autores, en esta segunda etapa se producen manifestaciones más complejas de la risa, que mantienen la conexión con lo bajo, pero que también incorporan distintos grados de seriedad. Estamos ante una fusión de estéticas que caracteriza lo mejor de la literatura clásica (además de Cervantes, Rabelais, Shakespeare, Goethe). Con esta premisa, se abren tres direcciones en el análisis conjunto de las Novelas ejemplares, el Quijote de 1615 y el Persiles: Ios personajes 
serio-cómicos, la inserción de géneros simples orales, y la recuperación de lo mágico-maravilloso. He aquí donde encontramos el mayor aporte del libro, al menos en términos teóricos, sobre todo en las dos últimas direcciones.

La causa de este cambio en la risa cervantina se encuentra, según el ensayo, en la distinta valoración cultural de este fenómeno alrededor del año 1600. La sociedad del seiscientos avanza en el "proceso de la civilización" hacia unas formas más refinadas que truecan la burla violenta en sonrisa placentera y honesta. Notamos una laguna en la argumentación, puesto que el cambio, aunque evidente, es progresivo a lo largo de muchas décadas, y no puede establecerse un corte cualitativo con el cambio de siglo. Quizás pueda pensarse en una evolución interna del escritor, en consonancia, pero no dependencia, con la evolución social. Otro rasgo destacado en esta segunda etapa de Cervantes es el trabajo con la novedad, es decir, con el presente inmediato, lo que supone otro rasgo de modernidad y, sobre todo, la posibilidad de renovar géneros y símbolos tradicionales, como luego veremos.

En cuanto a los personajes cervantinos, se distingue entre "paroxísticos" (un rasgo cómico llevado al extremo, como El celoso extremeño), "en oxímoron" (La ilustre fregona, personaje bajo pero virtuoso) y "oscilantes" (cuyos mayores ejemplos son Don Quijote y Sancho Panza). En todos ellos se percibe el alejamiento de la univocidad estereotipada y puramente cómica (incluso en los personajes paroxísticos, que son parodia de símismos). En otras palabras, la incorporación de la seriedad permite matizar el carácter de los personajes y otorgarles una complejidad que, si bien los aleja de la simplicidad popular, los convierte en individuos.

Más novedosa resulta la segunda dirección del análisis, basada en la incorporación de los géneros cómicos orales en la escritura cervantina. Si bien se ha estudiado la relación de Cervantes con otros géneros escritos (desde el pastoril hasta la picaresca), es más difícil percibir la conexión con formas orales que, por su propia naturaleza, han dejado una huella más borrosa en la literatura. Entre otros, el ensayo explora las posibilidades del biòs folclórico en El licenciado Vidriera, de los géneros rústicos (epitalamio, pastolera) en el Quijote de 1615, y hace énfasis en el "caso", a menudo combinado con otros géneros menores ("caso-prueba", "casofábula", "caso-leyenda", etc.). En este sentido, el caso aparece en la base de varias novelas ejemplares, pero también se hace presente en las peripecias del Persiles (que, por lo tanto, no puede reducirse al esquema de la novela bizantina). Sin duda, el estudio de lo que Jolles llamara "formas simples" en la literatura escrita supone una vía de investigación importante, no solo para los estudios cervantinos.

No menos interesante es la recuperación de la dimensión mágico-maravillosa en la escritura cervantina, que representa otra forma de trabajar el universo de la risa y de la cultura popular sin reducirlas a la carcajada y al mero folclore. Este tratamiento genera obras tan originales como El coloquio de los perros, que a menudo desconcierta a la crítica por la mezcla de fantasía y costumbrismo. Por supuesto, también está presente en Don Quijote, principalmente a través de la figura del loco que encarna el protagonista, pero también mediante el simbolismo tradicional en episodios como el de la Cueva de Montesinos. Finalmente, este 
aspecto de la risa tiene cabida en el Persiles (piénsese en los licántropos), libro que muestra en este ensayo una cara cómica a menudo soslayada por la crítica.

En la última página del libro, se retoma la interpretación romántica de Schelling sobre Don Quijote, que se basaría en la lucha entre lo real y lo ideal. Para los autores, sin embargo, el conflicto central, extrapolable a toda la obra cervantina, reside en el enfrentamiento e hibridaciones entre las estéticas de la risa y de la seriedad. Es aquí donde se percibe la originalidad del libro y se encuentra un tercer argumento para defender su pertinencia: en complementariedad a los análisis de detalle filológico y a los de naturaleza sociológica, este ensayo explora las dimensiones estéticas de las obras, lo que suscita un estudio de gran amplitud y complejidad. 